Formulary, but in the meantime extra diligence is called for.

P D WILSON

Stobhill General Hospital,
Glasgow G21 3UW

S NATARAJAN

' Marks J. Reactions to dapsone. Lancet 1981 ;ii :585.

\section{Topical minoxidil in the treatment of alopecia areata}

SIR,-We read with interest of the experience of Dr David A Fenton and Dr John D Wilkinson in treating alopecia with $1 \%$ topical minoxidil (8 October, p 1015).

In an open study we treated four patients with alopecia areata and six patients with alopecia totalis with a $1 \%$ minoxidil cream (crushed minoxidil tablets as many as will suffice, Metosyn diluent to $100 \%$ ). The duration of alopecia areata at entry to the study ranged from five months to 14 months (median seven months), and of alopecia totalis from one to 20 years (median four years). The minoxidil cream was applied to the affected areas twice daily for four to six months. Patients were assessed monthly and serial photographs were taken.

No patient with alopecia totalis and only one patient with alopecia areata showed any improvement over this period. One patient with alopecia totalis progressed to alopecia universalis during the study. The remaining nine patients and an additional patient with alopecia totalis (duration two years) were included in the second part of the study. Three per cent minoxidil lotion (crushed and filtered minoxidil tablets as many as will suffice, propylene glycol $10 \%$, distilled water $20 \%$, and alcohol to $100 \%$ ) was applied twice daily for four months. Again there was no response in alopecia totalis. Complete recovery in two of the four patients with patchy alopecia areata occurred. Systemic side effects were not observed.

Topical minoxidil in concentrations of $1 \%$ and $3 \%$ appear to be safe but our initial results have been disappointing. Minoxidil is an expensive drug and a three month supply of $3 \%$ minoxidil lotion $(90 \mathrm{ml})$ prepared from crushed tablets costs more than $£ 70$. We do not think that it should be used on an "ad hoc" basis until further studies have confirmed its efficacy in alopecia areata.

Clodagh M King BRIAN HARROP VINAY K DAVE

Skin Hospital,
Manchester M3 3HL

SIR, - We were interested to read the article on topical minoxidil in the treatment of alopecia areata (8 October 1983, p 1015). After reading earlier reports of the topical efficacy of this drug $^{1}$ we selected nine patients with either extensive alopecia areata (three) or alopecia totalis (six), unresponsive to treatment. Ages ranged from 4 years to 65 years and all had had their disease for at least 18 months. We used $1 \%$ minoxidil in unguentum Merck, $0.5 \mathrm{~g}$ daily $(0.25 \mathrm{~g}$ daily for two children) for a minimum of three months.

Of the nine, only one patient with a 13 year history of intermittent but extensive alopecia areata of the ophiasiform type grew sufficient hair to discard her wig. One child of 4 years with two episodes of alopecia totalis in 18 months had had good regrowth of vellous hair over the scalp and terminal hairs on the eyebrows. Two other patients grew some vellous and a few terminal hairs only. No side effects were reported apart from some irritation, possibly from the base, in a patient with adult pattern of atopic eczema. Blood pressures remained stable throughout.

We would agree with Dr David A Fenton and Dr John D Wilkinson that topical minoxidil may be a useful and safe method of treating alopecia areata, but it is disappointing that it seems unlikely to benefit those with alopecia totalis of long standing. The cost to the NHS in the Royal Liverpool Hospital is $£ 5.94$ for $20 \mathrm{~g}$.

$S$ LEWIS-JONES

Department of Dermatology, Royal Liverpool Hospital,
Liverpool L69 $3 \mathrm{BX}$

${ }^{1}$ Lomas SM. Minoxidil ointment and liquid. Pharmaceutical fournal 1982;229:193.

\section{Trimming fat or cutting bone?}

SIR,-Many consultants in the hospital service are convinced that the financial cuts, which started with "rationalisation" about two years ago and which have, since the recent election, culminated in the severe cuts in spending and manpower recommended in circular $\mathrm{HC}(83) 16$, will have a most damaging effect on the standard of patient care, despite ministerial assurances to the contrary.

The most serious effects are resulting from ward closures, many of which have already occurred with many more to come before March 1984. These closures inevitably place severe pressures on the nursing staff in the remaining wards. The patients will not go away. In this district our largest hospital (592 beds) has already had two acute wards closed with two more to come-making a total loss of 90 acute beds. Apart from the day to day stresses that will fall on the remaining wards, there arises also the serious consequence that our ability to accept patients from a major catastrophe-for example, a rail crash-will be greatly diminished.

It is clear that the government failed to take advice at the clinical level before issuing circular $\mathrm{HC}(83) 16$. Does tragedy have to occur before the government will modify its stance ?

As the British constitution does not contain a bill of rights, perhaps the BMA and all the royal colleges should consider the possibility of taking out a High Court injunction to halt governmental financial cuts in the hospital services where it can be clearly seen by clinicians that such cuts will result in a serious deterioration in the standard of patient care.

West Hill Hospital,

JAMES A RYAN Dartford, $2 \mathrm{HP}$

\section{Privatisation of hospital laundry service}

SIR,-The government plans to compel health authorities to put hospital laundry, catering, and domestic services out to tender. Some private contractors may well prove cheaper, more efficient, and less vulnerable to industrial action while relieving the health authorities of capital spending and simplifying administration. These assumptions are, how- ever, untested. The Health Service is being subjected to an experiment which may in many cases prove disastrous to the comfort and safety of patients and to the smooth running of our hospitals.

Ministerial interference aimed at encouraging privatisation has already delayed by at least a year long overdue upgrading of the hospital laundry at Barrow in Furness. This laundry was originally built for the workhouse but now serves the six hospitals on the Furness peninsula. A cramped and dilapidated building, mountains of dirty linen, rusty leaky clapped out machines, and puddles on the cracked concrete floor make a picture of typical NHS neglect and squalor. The $\mathbb{D}$ machines break down so often that the wards and theatres no longer have enough clean linen. The result : empty linen cupboards; unchanged $\overrightarrow{0}$ bedsheets; patients kept out of bed; babies nursed in towels or flannel nappies; surgeons and theatre nurses clothed in ill fitting rags; delayed theatre lists-we have seen all this and more. Paper sheets and pillowcases are now commonplace.

Plans for a modernised $£ 600000$ laundry have been ready for years; work should now be under way for completion in time for the new Furness General Hospital, due to open next summer. Meddling by the health minister has already cost five months' delay in haggling with the only large laundry in the area, which does not have a major works either in or near Barrow. Now the government require three tenders, so the complex and costly business of costings, examination of alternative schemes, drawing up of contracts, disputes with contractors, committees, red tape, etc, starts up all over again.

A place like Barrow does not have firms large or experienced enough to take on ancillary hospital services. Whenever a new hospital is built, contracting out will add to the chaos of present planning procedures. Nor can we be sure of efficient services; entrepreneurs can be just as guilty of incompetence and inefficiency as public servants-and are more likely to be dishonest. The unions will be angry at redundancies and the loss of protection of earnings.

Finally the government will lose control of costs-the private firms will be able to screw us for what they can get. And our laundries will be gone for ever.

Department of Paediatrics,

North Lonsdale Hospital, Barrow in Furness,

R J RowlatT

\section{Corrections}

\section{Congenital toxoplasmosis}

We regret that an error occurred in the letter from Dr H Williams and others (15 October, p 1140). In the third sentence of the third paragraph the range of infections should have read "from one in 300 to one in 1400 pregnancies" and not "from one in 300 to one in 400 pregnancies."

\section{New criteria and classification for diabetes mellitus}

We regret that an error occurred in the letter from Mr C Sanderson (15 October, p 1142). The traditional units for the glucose concentration $6 \mathrm{mmol} / 1$ should have read " $108 \mathrm{mg} / 100 \mathrm{ml}$ " not "198 mg/100 ml." . 